\title{
Metallic Ions in Organs of Rats Injected with Metallic Particles of Stainless Steel 316L and Ti6Al4V Alloy
}

\author{
Silvia Helena Giertz, ${ }^{\text {a }}$ Beatriz Luci Fernandes ${ }^{\mathrm{a}, \mathrm{b} *}$, \\ Carlos Roberto Fernandes ${ }^{\mathrm{b}}$, Celia Regina Cavichiolo Franco ${ }^{\mathrm{c}}$ \\ ${ }^{a}$ Pontifical Catholic University of Paraná - PUCPR, Curitiba - PR, Brazil \\ ${ }^{\mathrm{b}}$ Institute Grade of Basic Sciences - IGCB, Schroeder - SC, Brazil \\ ${ }^{\mathrm{C}} \mathrm{Federal}$ University of Paraná - UFPR, Curitiba - PR, Brazil
}

Received: June 3, 2009; Revised: January 21, 2010

\begin{abstract}
Despite the interest in identifying systemic effects caused by the metallic particles released from long term metallic implants in the body, few works support reliable conclusions about the effects of those particles in organs. The aim of the present work is to look for damages in tissues of liver, kidney, lung and heart of rats submitted to injection of Hank's solution contained particles of Ti6A14V alloy and Stainless Steel 316L, obtained by metal friction. The particles size ranges from 50 to $200 \mu \mathrm{m}$ for the Ti alloy and from 100 to $500 \mu \mathrm{m}$ for the $316 \mathrm{~L}$. Tissues isolated from the organs after the euthanasia were prepared and analyzed in an optical microscope and Energy Dispersive Spectrometer (EDS). Lesions caused by an inflammatory response such as strange body epithelioid granuloma and giant cells were found in some of the tissues containing yttrium and aluminum.
\end{abstract}

Keywords: metallic implants, particles release, in vivo test, Ti6Al4V alloy, stainless steel $316 \mathrm{~L}$

\section{Introduction}

The insertion of metallic implants in the human body is supposed to restore damaged structures in regions where a good mechanical resistance is essential ${ }^{1}$. Metallic implants are useful for many patients, although aseptic loosening is one of the long-term complications ${ }^{2}$. Those implants are well known to release metallic particles ${ }^{3}$, about $0.15 \mu \mathrm{g} . \mathrm{cm}^{-2} /$ day from corrosion process that accumulate in the periprosthetic tissue and are transported to organs far from the implant site $^{4}$. For this reason, there is concern about the systemic effects that the metallic particles may cause.

Many clinical finds confirm the osteolysis as local effects of the particles released from implants, but little is known about its cumulative effects in organs because of the inherent difficulties in identification of those particles in patient organs and body fluids. Urban et al. ${ }^{5}$ demonstrate the importance of conducting studies on this issue. In their investigation, in the liver, spleen and abdominal para-aortic lymph nodes from twenty-nine dead patients who have had a total hip or knee replacement. Their finds reveal granulomatous inflammation in lymph node of seventeen patients, fibrosis in ten and the majority of para-aortic lymph node was stained black due to the high quantity of metallic particles. In one living patient, additionally studied, it was found epithelioid granulomatous consisting of epithelioid macrophages and multinucleated giant cells in lymph nodes, liver and spleen with abundant particles released from the Ti6Al4V alloy. Although titanium alloys are considered more biocompatible and corrosion resistant than other metallic biomaterials, there are evidences that there is no difference between stainless steel and titanium alloys regarding its metallic particles release and immune-inflammatory reactions when in contact with the tissues ${ }^{6}$.

Although there are many difficulties in analyze tissue from organs of patients, few works presents studies on the systemic effects of the particles using animal models because it is hard to simulate the effects on the human body accurately. However, there is a consensus that injection of metallic particles in peritoneal region of rats can be helpful to simulate the host response to implant debris in human beings ${ }^{7}$.

The purpose of this study was to determine the prevalence of produced particles of stainless steel $316 \mathrm{~L}$ and Ti6Al4V alloy in liver, kidney, lung and heart of rats and analyze its histopathological response, intended to contribute to understanding the impact of metallic particles released from implants in the organism.

\section{Materials and Methods}

To produce the particles, two billets in Ti6Al4V alloy and two in stainless steel $316 \mathrm{~L}$ were machined in order to fit one piece in the mandril of a drilling machine and other in a tool that avoided the clockwise rotation caused by the friction against the piece fixed on the mandril. During the friction process that occurred inside a stainless steel container, the pieces were maintained immersed in a solution composed by deionized water and $5 \mu \mathrm{g} \cdot \mathrm{mL}^{-1}$ of despacilin (antibiotic) $400 \mathrm{mg}$, to avoid contamination of the solution and, consequently, of the animals. The room temperature was kept in $20^{\circ} \mathrm{C}$.

The two pieces of the same alloy were frictioned against each other until about $1.000 \mathrm{~g}( \pm 0,001 \mathrm{~g})$ of particles was obtained. The particles were separated from the solution by filtration using a Büchner funnel and $28 \mu \mathrm{m}$ filter paper and dried in a laboratory oven. A sample of the particles was visualized in scanning electron microscopy (SEM), Figure 1, in order to assess the shape and size of the particles from each alloy. The size of the particles was determined by the Martin diameter method using the SEM images, and in order to evaluate the size dispersion it was determinate the coefficient of variation $(\mathrm{CV})$. 


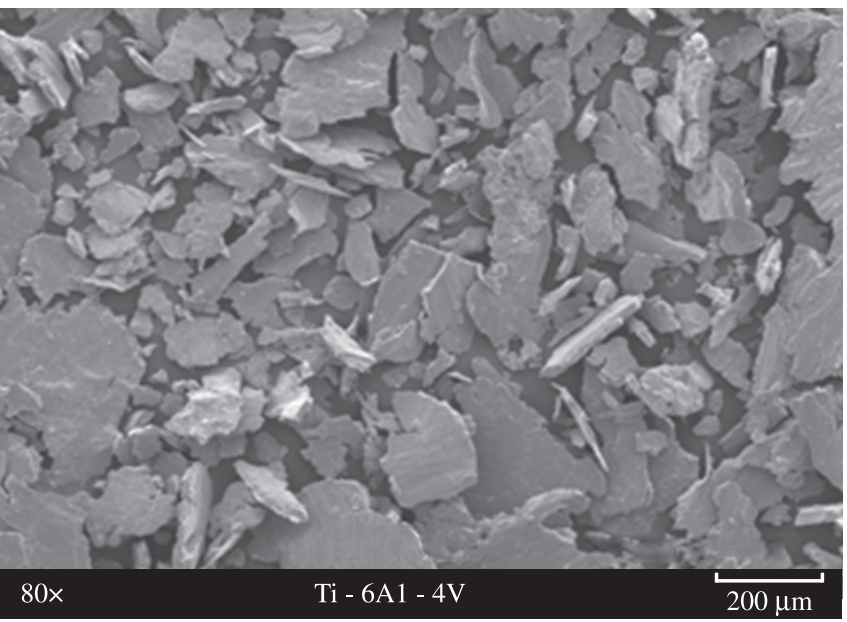

(a)

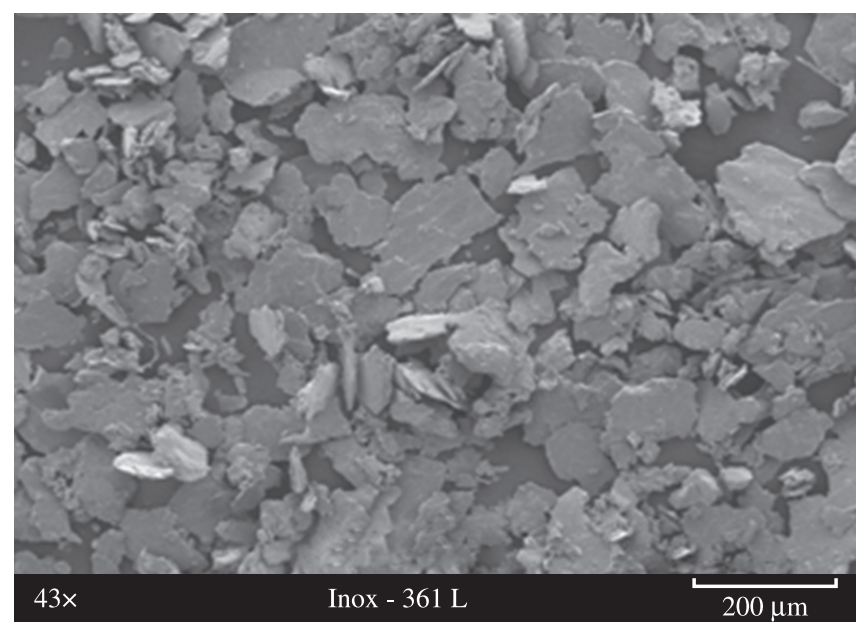

(b)

Figure 1. SEM images: (a) Particles of Ti6Al4V and (b) particles of stainless steel 316L.

Table 1. Results from the five samples which presented lesions.

\begin{tabular}{cclcc}
\hline Group & Organ & \multicolumn{1}{c}{ Lesion type } & Samples with lesions & Number of samples \\
\hline Ti6Al4V & heart & epithelioid granuloma & 1 & 41 \\
& liver & epithelioid granuloma and giant cells & 1 & 41 \\
SS 316L & heart & epithelioid granuloma and giant cells & 1 & \\
& lung & epithelioid granuloma and giant cells & 1 & 4 \\
Control & liver & epithelioid granuloma & 1 & 41 \\
\hline
\end{tabular}

The remained particles were sterilized in an autoclave at $120{ }^{\circ} \mathrm{C}$ during 20 minutes, and mixed in Hank's solution that was used as a vehicle for injection in the animals.

Thirty Wistar 40 days male rats, weighting about $250 \mathrm{~g}$ each, were used to perform the in vivo test, approved by the Local Ethical Committee (protocol 81.06/CEUA-PUCPR), and based on the ASTM 750-87(2007) standard. Ten rats for each alloy and ten for the control group were randomly chosen. Based on previous works of $\mathrm{Rae}^{8}$ and Pereira et al. ${ }^{9}$ the injection solution was prepared in a proportion of $3.75 \mathrm{mg}$ of particles in $1 \mathrm{~mL}$ of Hank's solution and injected at the maximum rate of $0.1 \mathrm{~mL} / \mathrm{s}$ in the peritoneum. In rats of the control group was injected $1 \mathrm{~mL}$ of Hank's solution without particles.

The animals were observed during 35 days maintained at $22{ }^{\circ} \mathrm{C}$ with a 12 hours light-dark cycle and ad libitum (free access to water and AIN-93G diet). At the thirty-fifth day, after euthanasia, the liver, kidney, lung and heart of the animals were appropriated extracted and the tissues from those organs were isolated and properly prepared for histopathological analysis according to the standard protocol that includes fixation, inserting in paraffin, cutting into wafer-thin sections and staining with hematoxylin plus eosin $(\mathrm{H}+\mathrm{E})$. The hematoxylin stains the cell nucleus in dark purplish-blue and the eosin stains the cytoplasm in pinkish-red color. The samples were analyzed searching for lesions in the tissues.

In order to identify metallic particles in tissues, from the lesioned tissues identified in optical microscopy, were chosen for EDS analysis: liver of the animal from the control group, liver of the animal injected with stainless steel 316L particles and heart (only organ affected) of the animal injected with Ti6Al4V alloy particles.

\section{Results}

It was prepared and analyzed 123 samples of tissues isolated from the animal organs. Only five of them presented tissue lesions,
Table 1, mostly composed by strange body epithelioid granuloma, Figure 2, found in the tissue isolated from the heart of an animal injected with Ti6A14V alloy particles. The Table 1 presents the results of the five samples.

The same granuloma and giant cells, Figures 3 and 4, were present in samples isolated from the liver, heart and lung of three different rats in which it was injected stainless steel $316 \mathrm{~L}$ particles. In the control group was found an epithelioid granuloma in the liver tissue of one of the rats, Figure 5. It was not found any lesions in the samples collected from the kidney of the animals.

Through the EDS test of the lesioned tissues, was identified yttrium in the sample isolated from the liver of a rat injected with stainless steel 316L particles, Figure 6, and aluminum from the sample isolated from the heart of a rat injected with Ti6Al4V alloy particles, Figure 7. Only chemical elements generally present in the body fluids were identified in the liver of a rat of the control group, Figure 8.

\section{Discussion}

The $316 \mathrm{~L}$ group more tissue lesions compared to the other two groups under investigation. Only five laminas from the 123 analyzed presented lesions corresponding to $0.04 \%$. This result is not too far from that obtained by Gaechter et al., 1979, apud Lewis and Sunderman ${ }^{4}$ of $0.07 \%$ ( 19 in 260 animals) of adverse reactions caused by the insertion of metallic rods in gluteal muscle of rats.

The particles produced by friction of the pieces of Ti6Al4V alloy and stainless steel $316 \mathrm{~L}$ presented similar geometries and size varying from 50 to $200 \mu \mathrm{m}(\mathrm{CV}=0,46)$ for the Ti6Al4V alloy and from 100 to $500 \mu \mathrm{m}$ for the stainless steel $316 \mathrm{~L}(\mathrm{CV}=0,66)$. These size variations between the alloys can be explained by the strain hardening of the Ti6Al4V alloy that occurred during the cold work at room temperature provoked by the friction ${ }^{10}$. The strain hardening fracture grains forming smaller particles than those formed by 


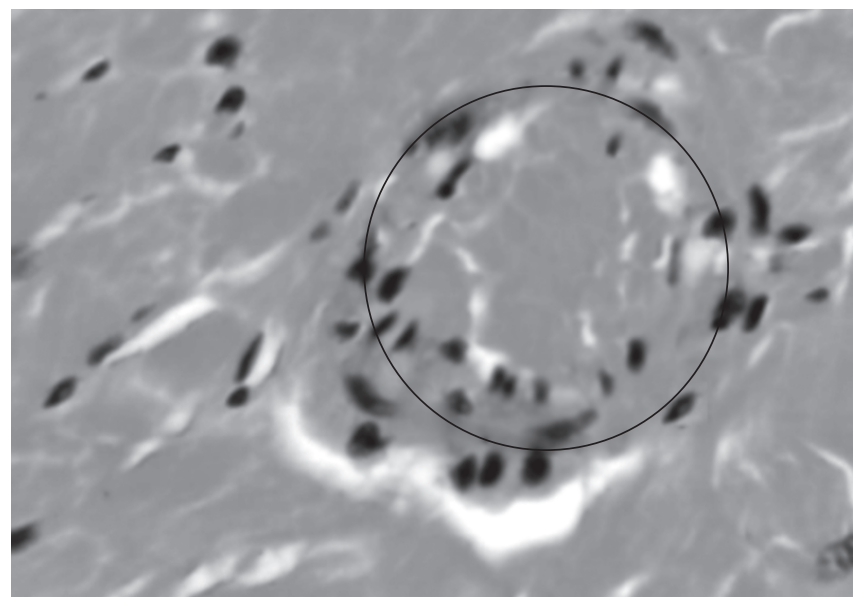

Figure 2. Sample of the heart tissue from a rat injected with Ti6Al4V alloy particles showing an epithelioid granuloma, 400x.

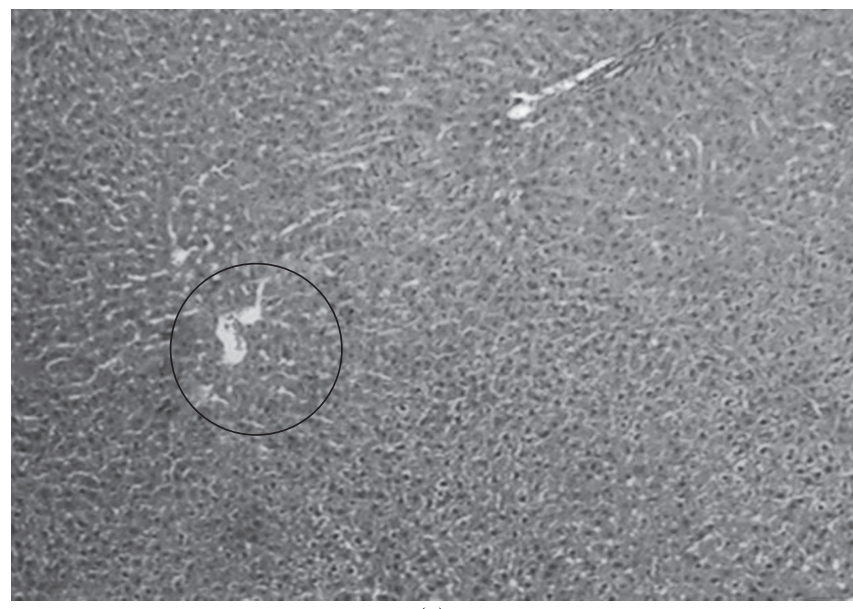

(a)

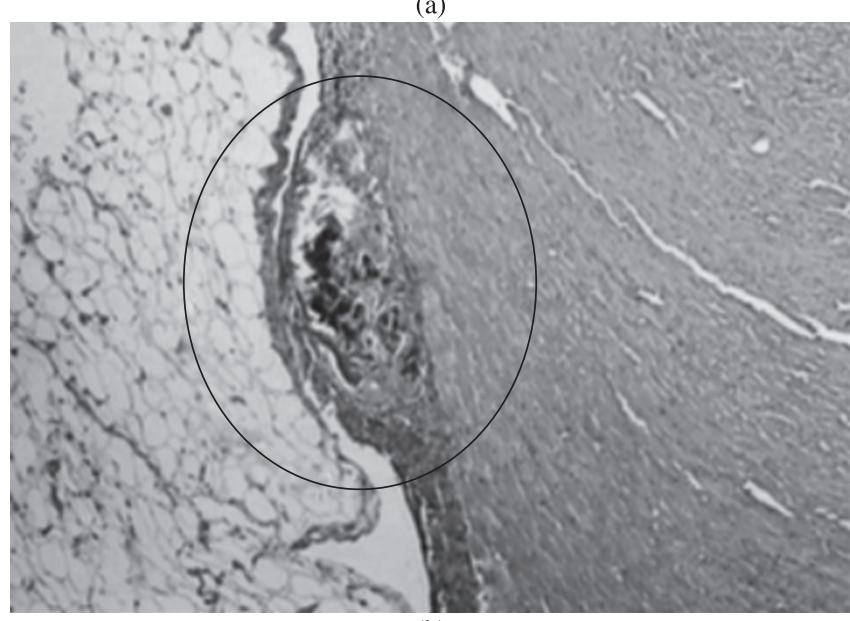

(b)

Figure 3. Samples from rats injected with stainless steel 316L particles: (a) liver of a rat showing an epithelioid granuloma, $40 \times$ and (b) heart showing a strange body epithelioid granuloma and grouped phagocytes contained indigested material, $1000 \times$

friction of stainless steel 316L. However, energy storage within the metal increases its chemical reactivity and may cause severe inflammatory response from the body ${ }^{11}$. The high values of the Coefficients of Variation show that the friction of the metals produces a wide range

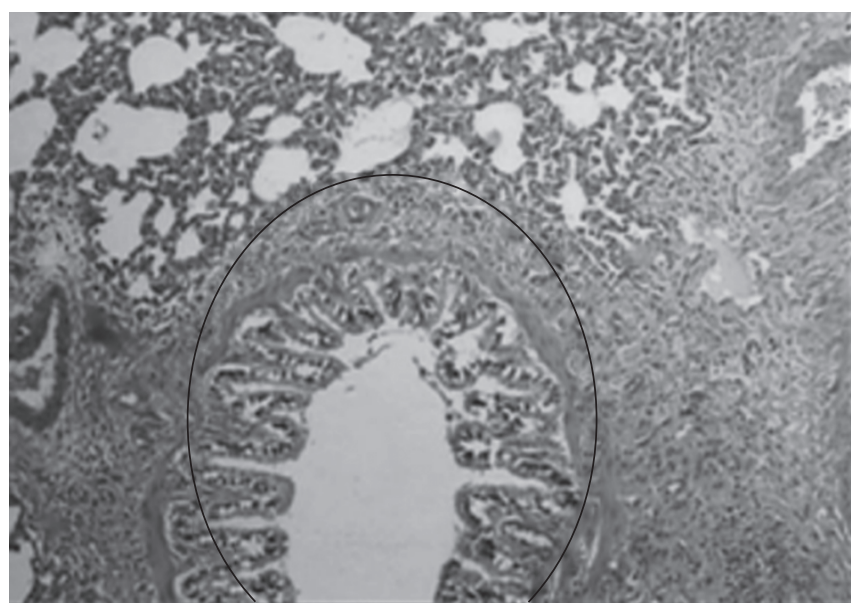

(a)

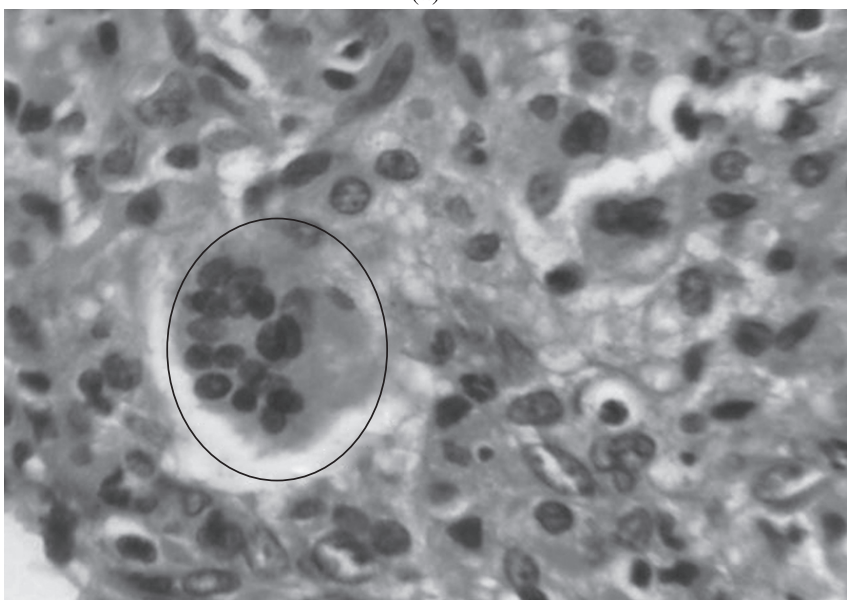

(b)

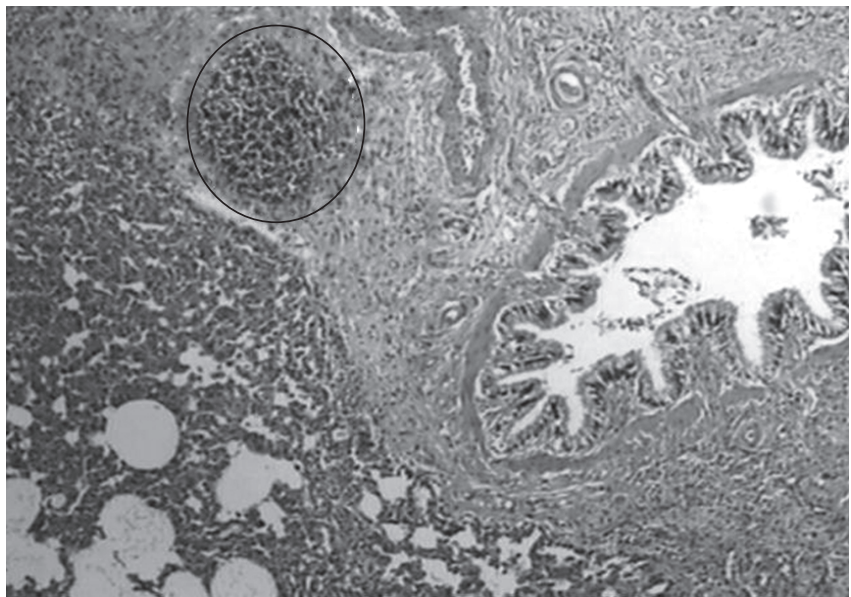

(c)

Figure 4. Samples from the lung of a rat injected with stainless steel 316L particles showing: (a) an initial pneumonia, $40 \times$ (b) giant cells, 400× and (c) a strange body epithelioid granuloma, $40 x$.

size of particles with the same parameters which makes the method attractive for many applications.

The size range of metallic particles isolated from the adjacent tissue of loose human prosthesis is between 0.3 and $2.0 \mu \mathrm{m}^{7}$, although metal irregular particles up to $5 \mu \mathrm{m}$ can be found in macrophages and extracellular site ${ }^{12}$. According to $\mathrm{Choi}^{13}$, particles released in the organism with size between 1.5 and $5.0 \mu \mathrm{m}$ are absorbed by mac- 


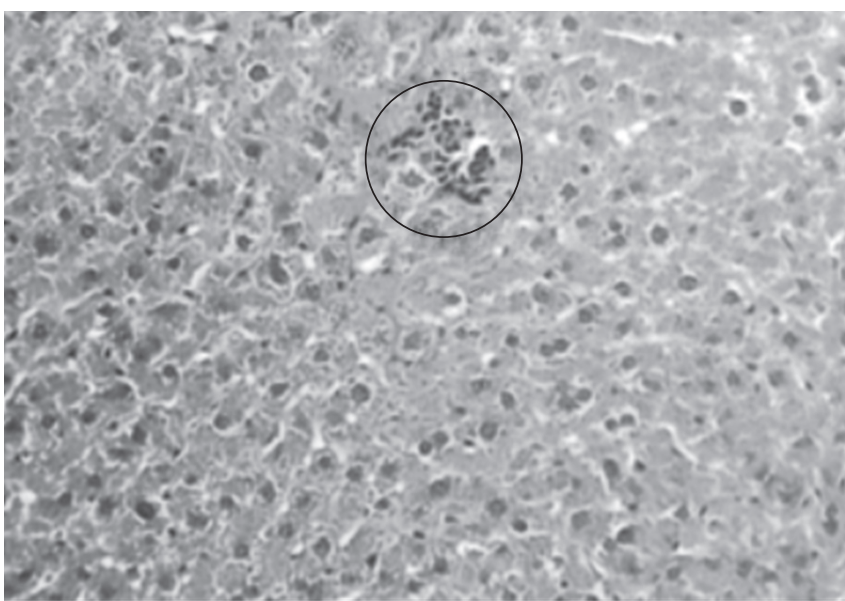

Figure 5. Sample from the liver of a rat injected with Hank solution without metallic particles (control group). It is possible to visualize a small epithelioid granuloma, 1000x.

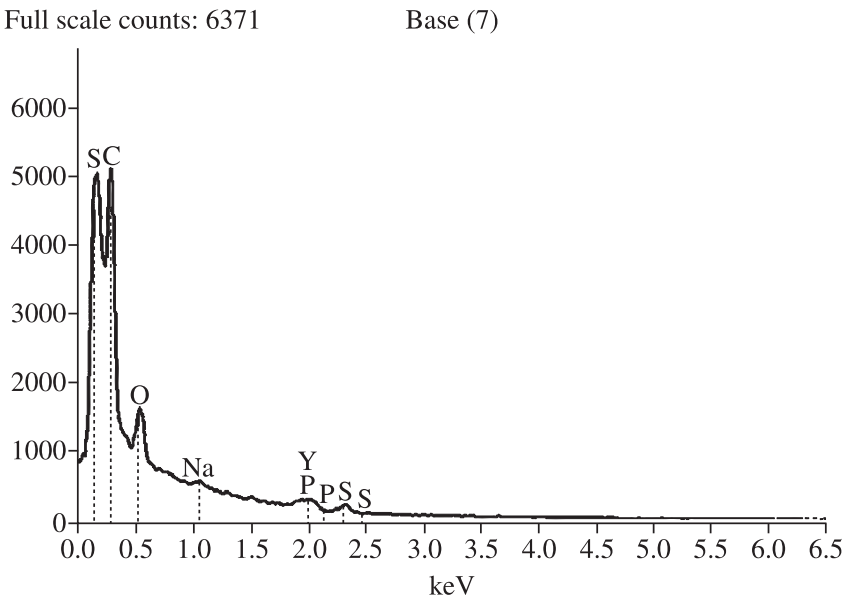

Figure 6. EDS plot analysis showing a peak of yttrium in the sample isolated from the liver of a rat injected with stainless steel $316 \mathrm{~L}$ particles.

rophages and transported, through the blood stream, to the organs and can be found in heart, lung, brain and lymph nodes. However, particles larger than $10 \mu \mathrm{m}$ remain at the local where were produced or introduced and are encapsulated by the organism, inducing giant cell reaction ${ }^{2}$. Although the particle sizes produced in this work were bigger than $10 \mu \mathrm{m}$, elements present in alloys composition were detected in organs far from the site of injection, showing the dissolution of the alloy in ions small enough to interact with cells and provoke imuno-inflammatory reactions.

Immediately after the implantation of a metallic component, adsorption of proteins from the body fluids on the metallic surface and interactions with the adjacent tissues occur, involving redox reactions (electron exchange), hydrolysis and formation of metal-organic complexes. These events trigger denaturing of the tissues, changes of $\mathrm{pH}$ and a sequence of electrochemical reactions. The corrosion by-products, like metallic ions, can accumulate in the periprosthetic tissue and reach organs far from the implant site. Besides, the ions carry an electrical charge and easily bond with natural proteins changing their functions ${ }^{14}$.

The oxide formed on the Ti6Al4V alloy surface that is responsible by its relatively chemical stability when in contact with the body fluids, is composed by $\mathrm{TiO}_{2}$ and $\mathrm{Al}_{2} \mathrm{O}_{3}$, therefore, the ions $\mathrm{Al}$ and $\mathrm{Ti}$ are more susceptible to be released from the alloy ${ }^{15}$. Since the AIN-93G

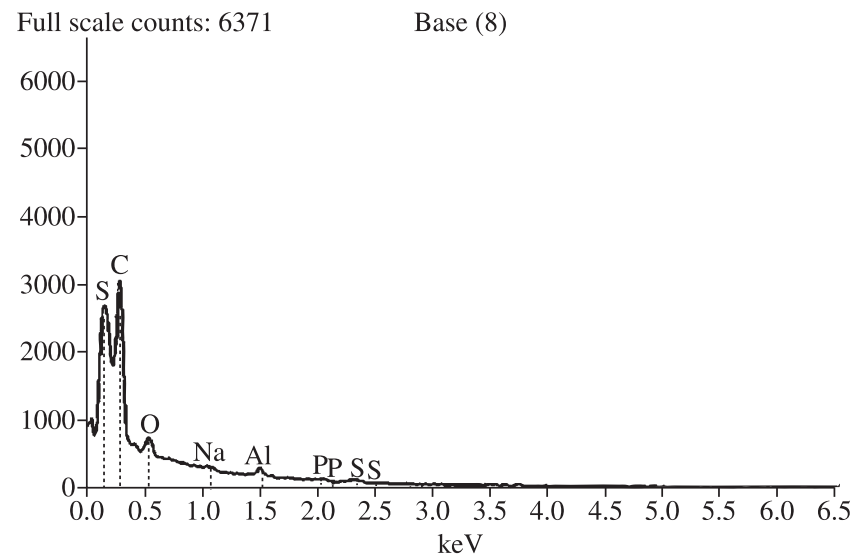

Figure 7.EDS plot analysis showing a peak of aluminum in the sample isolated from the heart of a rat injected with Ti6Al4V alloy particles.

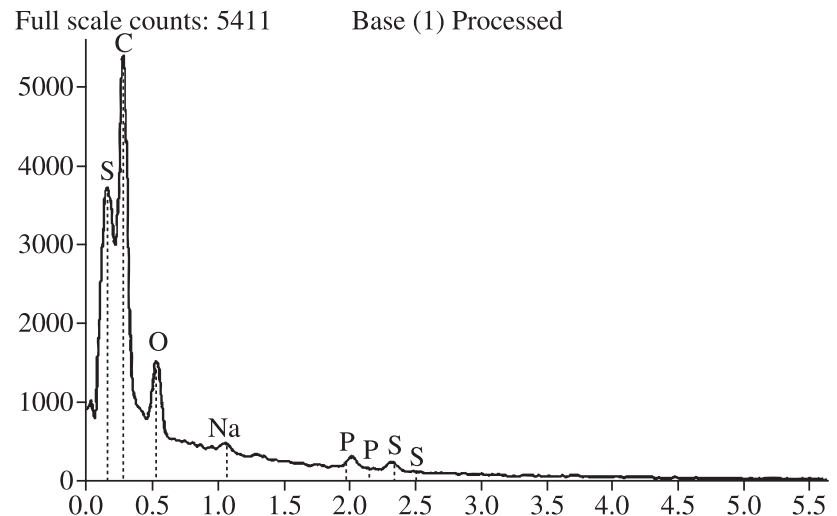

Figure 8. EDS plot analysis showing chemical elements generally present in the body fluids in the sample isolated from the liver of the rat of the control group.

diet did not contain aluminum in its composition as well as the feed accessories, is possible to suggest that the titanium alloy as the source for the Aluminum in the tissue isolated from the heart of the animal injected with this alloy. Additionally, Rubio et al. ${ }^{16}$ reported that the aluminum ions are transported by albumin and transferrin to the organs like brain, liver, spleen, lung and kidney. However, no traces of Ti were found although the film in the titanium alloy is composed by $\mathrm{TiO}_{2}$ and other titanium oxides. The titanium ions react easily with hydroxyl radicals and anions forming salts and oxides in body fluid not allowing its combination with biomolecules what could be the cause of no identification of titanium ions in the rats organs ${ }^{17}$.

The liver was affected in 2 rats: one injected with stainless steel 316L particles and other with Hank's solution without metallic particles. Since the liver is the major waste organ of the body, it is reasonable to find metal particles or adverse reactions there. The strange body epithelioid granuloma found in the control group has no connection with the injected metals, since the Hank solution does not have the same chemical elements present in the alloys. The Hank solution has composition close to the biologic fluids $\left(\mathrm{CaCl}_{2} 0.1855\right.$, $\mathrm{MgSO}_{4} .7 \mathrm{H}_{2} \mathrm{O} 0.204, \mathrm{KCl} 0.4, \mathrm{~K}_{2} \mathrm{PO}_{4} 0.06, \mathrm{NaHCO}_{3} 0.35, \mathrm{NaCl} 8.00$, $\left.\mathrm{Na}_{2} \mathrm{HPO}_{4} 0.0475, \mathrm{C}_{6} \mathrm{H}_{12} \mathrm{O}_{6} 1 \mathrm{~g} . \mathrm{L}^{-1}\right)$, therefore, it was not expected to occur adverse reactions in the animals belonged to the control group. The possible cause of the granuloma formation is the injection of the solution at the peritoneum site, where the liver is allocated. The needle could reach the liver and could be the responsible for the localized inflammatory response. 
In the stainless steel group it was found, in the liver of one of the animals, the yttrium, a chemical element that can be added in the stainless steel composition in order to improve its corrosion resistance by enhancing the superficial oxide passive film with yttrium oxides $^{18}$. These oxides dissolve in fluids containing salts like the body fluids, releasing yttrium ions ${ }^{19}$. No other element from this metal was found. When metallic particles were injected, however, is possible that an ionic dissociation occurred, and the ions were carried out from the insertion site, allocating in organs that were not analyzed in this work.

Although the yttrium has been used as treatment of some disease as rheumatoid arthritis, Hirano et al. ${ }^{20}$ showed acute toxicity of yttrium in rats intravenously injected with this metal. It appears in colloidal material composed by proteins and minerals phagocytes in the liver and spleen, when the doses are superior to $0.2 \mathrm{mg} / \mathrm{rat}$. Higher doses, about $1 \mathrm{mg} / \mathrm{rat}$, caused acute hepatic injury indicating that the liver is a target organ for this element, what agree with the results obtained in the present work.

\section{Conclusion}

The friction of metals produces a large range size of particles, and through adequate separation process can easily provide particles for in vivo tests intended to evaluate the body host response to metallic particles. The results confirm that the metallic particles, even larger than those considered for phagocytosis in the literature, dissociate in ions when in contact with the body fluids that are carried far away from the site of injection accumulating in preferential organs, especially in those considered waste organs of the body as liver and kidneys. Comparison of the size of the particles from the site of injection with the size of the particles accumulated in the organs should be very useful. However, in order to perform the analysis into the organs, they must be sectioned in thin plane sections and digested in a series of procedures that can alter the size of the metallic particles, depending on its susceptibility to the chemicals used. In addition, the sections analyzed represented an infinitesimal part of the organ and many particles are missed inducing to wrong conclusions. Regarding the in vivo test, there is no consensus about the appropriate animal model that can provide a clear indication of the systemic effects that metallic ions can cause in the human being. However, the present work testified that metallic ions are disseminated in the organism and its presence cause cellular abnormalities.

\section{References}

1. Fonseca KB, Pereira HH and Silva SN. Avaliação de falhas e implantes metálicos coxo-femoral e joelho retirados de pacientes. Revista Matéria. 2005; 10(3):472-480.

2. Ito $\mathrm{S}$, Matsumoto T, Enomoto $\mathrm{H}$ and Shindo H. Histological analysis and biological effects of granulation tissue around loosened hip prostheses in the development of osteolysis. Journal of Orthopaedic Science. 2004; 9(5):478-487.

3. Jacobs JJ, Hallab NJ, Urban RM and Wimmer MA. Wear particles. Journal of Bone \& Joint Surgery American Volume. 2006; 88(Suppl 2):99-102.
4. Lewis CG and Sunderman W. Metal carcinogenesis in total joint arthroplasty. Clinical Orthopaedics and Related Research. 1996; 329(Suppl):S264-S268.

5. Urban RM, Jacobs JJ, Tomlinson MJ, Gavrilovic J, Black J and Peoch M. Dissemination of wear particles to the liver, spleen and abdominal lymph nodes of patients with hip or knee replacement. Journal of Bone \& Joint Surgery American Volume. 2000; 8(4):457-477.

6. Voggenreiter G, Leiting S, Brauer H, Leiting P, Majetschak M, Bardenheuer $\mathrm{M}$ et al. Immuno-inflammatory tissue reaction to stainlesssteel and titanium plates used for internal fixation of long bones. Biomaterials. 2003; 24(2):247-254.

7. Howie WD, Rogers SD, McGee MA and Haynes DR. Biologic effects of cobalt chrome in cell and animal models. Clinical Orthopaedics and Related Research. 1996; 329(Suppl):S217-S232.

8. Rae T. Study on the effects of particulate metals of orthopaedic interest on murine macrophages in vitro. Journal of Bone \& Joint Surgery British Volume. 1975; 57B(4):444-450.

9. Pereira ML, Abreu AM, Sousa JP and Carvalho GS. Chromium accumulation and ultrastructural changes in the mouse liver caused by stainless steel corrosion products. Journal of Materials Science: Materials in Medicine. 1995; 6(9):523-527.

10. Vanderhasten M, Rabet L and Verlinden B. AME High temperature deformation of Ti6Al4V at low strain rate. Metalurgija. 2005; 11:195-200.

11. Papps AM and Cohen J. Toxicity of metal particles in tissue culture: part I: a new assay method using cell counts in the phase of replication. Journal of Bone \& Joint Surgery American Volume. 1968; 50(3):535-547.

12. Case CP, Langkamer VG, James C, Palmer MR, Kemp AJ, Heap PF et al. Widespread dissemination of metal debris from implants. Journal of Bone \& Joint Surgery British Volume. 1994; 76B(5):701-712.

13. Choi MG, Koh HS, Kluess D, O'Connor D, Mathur A, Truskey GA et al. Effects of titanium particle size on osteoblast functions in vitro and in vivo. Proceedings of the National Academy of Science of the United States of America. 2005; 102(12):4578-4583.

14. Soontornvipart K, Necas A and Dvorak M. Effects of metallic implant on the risk of bacterial osteomyelitis in small animals. Acta Veterinaria (Belgrade). 2003; 72:235-247.

15. Morais LS, Serra GG, Muller CA, Palermo EFA, Andrade LVR, Meyers MA et al. Liberação in vivo de íons metálicos por mini-implantes ortodônticos de Ti-6Al-4V. Revista Matéria. 2007; 12(2):290-297.

16. Rubio JC, Garcia-Alonso MC, Alonso C, Alobera MA, Clemente C, Munuera L et al. Determination of metallic traces in kidneys, livers, lungs and spleens of rats with metallic implants after a long implantation time. Journal of Materials Science: Materials in Medicine. 2008; 19(1):369-375.

17. Hanawa T. Metal ion release from metal implants. Materials Science \& Engineering C. 2004; 24(6-8):745-752.

18. Riffard F, Buscail H, Caudron E, Cueff R, Issartel C and Perrier S. Yttrium implantation effect on 304L stainless steel high temperature oxidation at $1000{ }^{\circ} \mathrm{C}$. Journal of Materials Science. 2002; 37(18):3925-3933.

19. Takaya M, Shinohara Y, Serita F, Ono-Ogasawara M, Otaki N, Toya T et al. Dissolution of functional materials and rare earth oxides into pseudo alveolar fluid. Industrial Health. 2006; 44(4):639-644.

20. Hirano S, Kodama N, Shibata K and Suzuki KT. Metabolism and toxicity of intravenously injected Yttrium Chloride in rats. Toxicology and Applied Pharmacology. 1993; 121(2):224-232. 
